\section{Esterase Activity of Pepsin}

IT is known that many proteolytic enzymes-trypsin, chymotrypsin, thrombin, papain and others-hydrolyse peptide, amide and ester bonds. Pepsin, however, is generally believed to hydrolyse the peptide bonds only, without exhibiting the esterase activity ${ }^{1}$. This conclusion is based on observations which suggest that pepsin does not hydrolyse the ester bonds in several esters of $\mathrm{N}$-substituted amino-acids and peptides, but no special investigation of the esterase activity of pepsin has been published.

In view of the possible significance of esterase activity in the action of pepsin, we have examined its effect on some esters. Tho $\mathrm{N}$-substituted aromatic amino-acid esters differing in the structure of the alcoholic component were chosen as substrates and the following were used: $\mathrm{N}$-acetyl-L-tyrosine ethyl ester, L-phenylalanine benzyl ester (the corresponding $\mathrm{N}$-substituted phenylalanine ester could not be used as it was insoluble in the experimental conditions), and $\mathrm{N}$-acetyl-L-phenylalanyl-L-phenyllactic acid. Effect of pepsin on the N-acetyl-L-phenylalanyl-x-phenylalanine methyl ester, which could bo expected to be hydrolysed, was investigated as well.

N-Acetyl-L-phenylalanyl-L-phenylalanine methyl ester (APPMe) and N-phenylalanyl-L-phenyllactic acid (APPL) were prepared by the method of mixed anhydrides from $\mathrm{N}$-acetyl-L-phenylalanine and L-phenylalanine methyl ester and L-phenyllactic acid, respectively.

Twice-crystallized pepsin (Nutritional, Biochemical Corporation) was used. Some experiments were performed with pepsin and pepsinogen purified on a DEAE-cellulose column ${ }^{2}$.

The effect of pepsin on the ester substrates was investigated at $p \mathrm{H} 2-4$ at $37^{\circ} \mathrm{C}$ during $20-48 \mathrm{~h}$; the concentrations of substrate and enzyme were $2.7 \times 10^{-8} \mathrm{M}$ and $2.7 \times 10^{-5} \mathrm{M}$, respectively. Because of limited solubility of APPL and APPMe, all the experiments were performed in the presence of 10-15 per cent of ethanol.

The cleavage of the ester bond was estimated by the hydroxamate reaction, by the method of Hestrin ${ }^{8}$. After 20-min treatment by hydroxylamine, $\mathrm{HCl}$ (about $4 \mathrm{~N}$ ) was added, followed, after incubation for $2 \mathrm{~min}$, by a 10 per cent solution of $\mathrm{FeCl}_{3} \cdot 6 \mathrm{H}_{2} \mathrm{O}$ in $0.1 \mathrm{~N} \mathrm{HCl}$. Optical density at $540 \mathrm{~m} \mu$ (spectrophotometer $S F-4$ ) was immediately measured in filtrates of these samples.

Table 1. Emfect of Pepsin on Some Esters

\begin{tabular}{ccccccccc} 
Substrates & ATEE & \multicolumn{1}{c}{ APPM } & \multicolumn{2}{c}{ PBE } & \multicolumn{2}{c}{ APPL } \\
$p$ H & 2 & 4 & 2 & 4 & 2 & 4 & 2 & 4 \\
$\begin{array}{c}\text { Hydrolysis: } \\
\text { (per cent) }\end{array}$ & 0 & 0 & 0 & 0 & 0 & 0 & 30 & 0
\end{tabular}

The data presented in Table 1 show that after incubation of pepsin with the N-acetyl-L-tyrosine ethyl ester (ATEE) and $\mathrm{N}$-acetyl-L-phenylalanyl-L-phenylalanine methyl ester (APPMe) no decrease in the quantity of esters could be detected although the cleavage of the peptide bond occurred in the course of incubation of APPMe with pepsin. No cleavage of the ester bond was noted in experiments with phenylalanine benzyl ester (PBE). But after the incubation of $\mathrm{N}$-acetyl-L-phenylalanyl-L-phenyllactic acid (APPL) with pepsin at $p \mathrm{H} 2 \mathrm{a}$ decrease in the quantity of ester was observed. Table 1 shows that cleavage of APPL at $p \mathrm{H} 2$ during $48 \mathrm{~h}$ is about 30 per cent. In control samples, whero APPL was incubated without the enzyme or in the presence of pepsin previously inactivated by alkali, no decrease in the quantity of ester was recorded. The hydrolysis of APPL undor the influence of pepsin was confirmed by silica-gel thin-layor chromatography in a methanol : ethylacetate (1: $5 \mathrm{v} / \mathrm{v}$ ) system, and iodine treatment. The outline taken from the chromatogram (Fig. 1) shows, in the control sample, a single spot of APPL. In the sample incubated with pepsin during 48 h at $p H 2$ a second spot

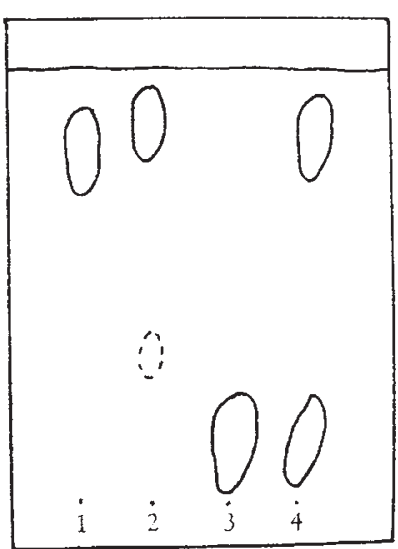

Fig. 1. Schema of silica-gel thin-layer chromatogram in methanolethylacetate $(1: 5, \mathrm{v} / \mathrm{v})$ system. 1, N-acetyl-L-phenylalanine; 2 L-phenyllactic acid; 3, control sample, APPL after 48-h incubation at $p \mathrm{H} 2$ without the enzyme; 4 , experimental sample, APPI after 48-h incubation at $p \mathrm{H} 2$ in presence of pepsin

was found. The position of this spot corresponds to $\mathrm{N}$-acetyl-L-phenylalanine and L-phenyllactic acid. Neither of these compounds is resolved in the solvent system used.

Cleavage of APPL under the influence of pepsin occurs at $p \mathrm{H}$ of about 2. No hydrolysis of APPL by pepsin at $p \mathrm{H}>3$ could be detected (Table 1).

It could be supposed that APPL is hydrolysed by some other enzyme probably present as an impurity in the pepsin preparation used. To exclude this possibility, we have investigated the effect of various preparations of pepsin on APPL. Three preparations of pepsin purified on a DEAE-cellulose column were used. One of these preparations was free from admixtures of gelatinase. In one of the experiments, pepsinogen activated directly in the experimental samples was used. All the preparations of pepsin used hydrolysed APPL. The degree of hydrolysis of the ester was about 20-30 per cent. Hydrolysis of APPL by pepsin could also be demonstrated with several different preparations of APPL.

The data presented here show that pepsin, like many other proteolytic enzymes, possesses the ability to hydrolyse ester bonds. But the ester bond, to be hydrolysed by pepsin, has to be formed not only by a specific aminoacid residue but also by a definite alcoholic component.

The data obtained are of interest in relation to the mechanism of pepsin action. They suggest that $\mathrm{CO}$. activation takes place during the action of pepsin. A similar conclusion may be drawn from the published data on the isotope exchange of oxygen in carboxyl groups of some $\mathrm{N}$-substituted amino-acids occurring under the influence of pepsin in $\mathrm{H}_{2} \mathrm{O}^{18}$ (refs. 4 and 5). On the other hand, it is known that pepsin catalyses transpeptidation of the 'amino transfer' type ${ }^{6,7}$. In view of these observations, it may be supposed that the cleavage of peptide bonds by pepsin includes a synchronous 'attack' on both $\mathrm{CO}$ - and NH-groups.

L. A. Lokshina

V. N. OREKHOVICH

V. A. Sklyankina

Institute of Biological and Medical Chemistry,

Academy of Medical Sciences of the U.S.S.R., Moscow.

1 Bovey, F. A., and Yanari, S. S., The Enzymes, edit. by Boyer, P., Lardy, H., and Myrback, K., 4, 63 (Academic Press Inc., New York-London, 1960 ).

Ginodman, L. M., in Modern Problems of Biochemistry, edit. by Orekhovich, V. N., 2, 54 (Moscow, 1962).

Hestrin, S., J. Biol. Chem., 180, 249 (1949)

- Sharon, N., Grisaro, V., and Neuman, H., Arch. Biochem. Biophys., 97, 219 (1962).

${ }^{5}$ Kozlov, L. V., Ginodman, L. M., Zolotarev, B. M., and Orekhovich, V. N. Doklady AN D.S.S.R., 146, 945 (1962).

- Neuman, H., Levin, Y., Berger, A., and Katchalski, E., Biochem. J., 78 $33(1959)$. 7 Fruton, J., Fujii, S., and Knappenberger, M., Proc. Nat. Acad. Sci., 47,
759 (1961). 